ABBREVIATIONS OF JOURNALS CITED

$\begin{array}{ll}\text { ASQ } & \text { Administrative Science Quarterly } \\ \text { AER } & \text { American Economic Review } \\ \text { AJES } & \text { American Journal of Economics and Sociology } \\ \text { AJS } & \text { American Journal of Sociology } \\ \text { APSR } & \text { American Political Science Review } \\ \text { AASS } & \text { Annals of the American Society of Political and } \\ & \text { Social Science } \\ \text { AR } & \text { Asiatic Review } \\ \text { CJPS } & \text { Canadian Journal of Economics and Political Science } \\ \text { CQ } & \text { China Quarterly } \\ \text { CIV } & \text { Civilizations } \\ \text { CSH } & \text { Comparative Studies in Society and History } \\ \text { EDCC } & \text { Economic Development and Cultural Change } \\ \text { FA } & \text { Foreign Affairs } \\ \text { HO } & \text { Human Organizations } \\ \text { IJPS } & \text { Indian Journal of Political Science } \\ \text { IJPA } & \text { Indian Journal of Public Administration } \\ \text { IAEA } & \text { Inter-American Economic Affairs } \\ \text { IA } & \text { International Affairs } \\ \text { IDR } & \text { International Development Review } \\ \text { ILR } & \text { International Labour Review } \\ \text { IO } & \text { International Organizations } \\ \text { IRAS } & \text { International Review of Administrative Sciences } \\ \text { ISSJ } & \text { International Social Science Journal (formerly } \\ & \text { Bulletin) } \\ \text { JAA } & \text { Journal of African Administration } \\ \text { JEH } & \text { Journal of Economic History } \\ \text { JPE } & \text { Journal of Political Economy } \\ \text { JP } & \text { Journal of Politics } \\ \text { MEJ } & \text { Middle East Journal } \\ \text { MPS } & \text { Midwest Journal of Political Science } \\ \text { PA } & \text { Pacific Affairs } \\ \text { PAD } & \text { Personnel Administration } \\ \text { PJPA } & \text { Philippine Journal of Public Administration } \\ \text { PQ } & \text { Political Quarterly } \\ \text { PSQ } & \text { Political Science Quarterly } \\ \text { PA(L) } & \text { Public Administration (London) } \\ \text { PA(S) } & \text { Public Administration (Sydney) } \\ & \end{array}$


PAR Public Administration Review

POQ Public Opinion Quarterly

PPR Public Personnel Review

RS Rural Sociology

SR Social Research

SSR Social Service Review

WPQ Western Political Quarterly

WP World Politics

WT World Today 



\section{DEVELOPMENT ADMINISTRATION}

AN ANNOTATED BIBLIOGRAPHY 
